\title{
Bipolar Radiofrequency Ablation of Painful Spinal Bone Metastases Performed under Local Anesthesia: Feasibility Regarding Patient's Experience and Pain Outcome
}

\author{
Adrian Kastler ${ }^{1, *}$, Daniel-Ange Barbé ${ }^{2}$, Guillaume Alemann ${ }^{3}$, Georges Hadjidekov ${ }^{4}$, Francois H. Cornelis 5 (i) \\ and Bruno Kastler ${ }^{6}$ \\ 1 Diagnostic and Interventional Neuroradiology Unit, CHUGA Grenoble Hospital, Université Grenoble Alpes, \\ 38400 Saint Martin d'Heres, France \\ 2 Imagerie Medicale Pays D’agde, 34300 Agde, France; danielange.barbe@gmail.com \\ 3 Cabinet Médial Clemenceau Selestat, 67600 Selestat, France; guillaume.alemann@gmail.com \\ 4 Department of Radiology, University Hospital Lozenets, 1407 Sofia, Bulgaria; jordiman76@yahoo.com \\ 5 Adult Radiology Department, Necker Hospital, Paris V University, 75015 Paris, France; \\ cornelisfrancois@gmail.com \\ 6 Department of Radiology, Memorial Sloan Kettering Cancer Center, New York, NY 10065, USA; \\ radioakastler@gmail.com \\ * Correspondence: akastler@chu-grenoble.fr
}

\section{check for}

updates

Citation: Kastler, A.; Barbé, D.-A.; Alemann, G.; Hadjidekov, G.;

Cornelis, F.H.; Kastler, B. Bipolar

Radiofrequency Ablation of Painful Spinal Bone Metastases Performed under Local Anesthesia: Feasibility Regarding Patient's Experience and Pain Outcome. Medicina 2021, 57, 966. https://doi.org/10.3390/

medicina57090966

Academic Editor: Alberto Tagliafico

Received: 14 July 2021

Accepted: 8 September 2021

Published: 15 September 2021

Publisher's Note: MDPI stays neutral with regard to jurisdictional claims in published maps and institutional affiliations.

Copyright: (c) 2021 by the authors. Licensee MDPI, Basel, Switzerland. This article is an open access article distributed under the terms and conditions of the Creative Commons Attribution (CC BY) license (https:// creativecommons.org/licenses/by/ $4.0 /)$.
Abstract: Background and objectives: To assess the pain relief of bipolar RFA combined or not with vertebroplasty in patients with painful vertebral metastases and to evaluate the feasibility and tolerance of the RFA procedure performed under local anesthesia. Materials and Methods: 25 patients (18 men, 7 women, mean age: 60.X y.o) with refractory painful vertebral metastasis were consecutively included between 2012 and 2019. A total of 29 radiofrequency ablation (RFA) procedures were performed under CT guidance, local anesthesia and nitrous oxide inhalation, including 16 procedures combined with vertebroplasty for bone consolidation purposes. Pain efficacy was clinically evaluated using the visual analogue scale (VAS) at day 1, 1 month, 3 months, 6 months and 12 months, and the tolerance of the procedure was evaluated. Results: Procedure tolerance was graded as either not painful or tolerable in $97 \%$ of cases. Follow-up postprocedure mean VAS score decrease was $74 \%$ at day 1: $6.6(p<0.001), 79 \%$ at 1 month: 6.6 ( $p<0.001), 79 \%$ at 3 months: $6.5(p<0.001), 77 \%$ at 6 months, and $79 \%$ at 12 months: $6.6(p<0.001)$. Conclusions: Bipolar RFA, with or without combined vertebroplasty, appears to be an effective and reliable technique for the treatment of refractory vertebral metastases in patients in the palliative care setting. It is a feasible procedure under local anesthesia which is well tolerated by patients therefore allowing to broaden the indications of such procedures. Field of study: interventional radiology.

Keywords: radiofrequency ablation; vertebroplasty; CT guidance; metastasis; local anesthesia; palliative care

\section{Introduction}

Bone is one of the most common metastatic sites, and $50 \%$ of pain experienced by cancer patients originates from bone metastases [1-4]. A spinal location may represent up to $80 \%$ of bone metastases [1]. In case of an extension to the neural structures, pain can be both radicular (exaggerated by percussion or palpation) and/or mechanical (exacerbated by movement) $[5,6]$. At advanced stages of the disease, pain may become intolerable, and refractory to conventional therapies causing walking disabilities, psychological and functional impact can thus impair markedly the quality of live [2-4,7].

Due to the short life expectancy of affected patients, treatment regimens are most often palliative rather than curative. Therefore, quick pain relief has become a priority in these patients suffering from refractory bone pain. 
Several conventional treatment options have been described including opioids, hormone therapy, chemotherapy, radiotherapy and surgery, which all have side effects and contraindications. Radiotherapy remains the gold standard, but up to $20 \%$ of patients are nonresponders, and the reported maximum benefit is obtained with a delay of 5-20 weeks after completion of treatment [8-10].

In these two past decades, interventional percutaneous image-guided techniques have emerged with satisfactory results in the management of vertebral metastasis such as vertebroplasty [11,12], radiofrequency ablation and microwave ablation [13-15], combined radiofrequency and cementoplasty [13,16] 16 or cryotherapy [17]. Bone percutaneous ablation is a mini-invasive treatment which presents several advantages, and it is a repeatable treatment with no limitation doses from the skin exposure compared to radiotherapy and remains a treatment with no interference with systemic treatments, especially those delaying healing, contrary to open-surgery procedures.

Most studies to date have assessed the effectiveness and safety of RFA with the use RF monopolar systems (which require grounding pads with a potential risk of skin burn) and were mainly performed either under general anesthesia or conscious sedation [18-20].

The objective of this study was to assess the pain relief of bipolar RFA combined or not with vertebroplasty in patients with painful vertebral metastases and to evaluate the feasibility and tolerance of the RFA procedures performed under local anesthesia and nitrous oxide ventilation.

\section{Materials and Methods}

Twenty-five consecutive patients (18 men, 7 women, mean age: $60 . \mathrm{X}$ y.o) were recruited between 2012 and 2019. All included patients presented painful spinal metastases refractory to all previously attempted conventional therapies, including opioids and radiotherapy, and the decision to undergo ablation was decided in a multidisciplinary meeting. The decision to perform adjunct vertebroplasty was made based on the location, type and extent of the lesion, and the Kostuik score [21] was used to predict fracture risk. In case of pathological fractures, cement injection was performed. Patient and lesion characteristics are detailed in Table 1. The average volume of treated tumors was $10.5 \mathrm{~mL}$. The mean Karnofsky performance status was 59 (range 40-80).

Exclusion criteria were as follows: patients with tolerable pain $(\mathrm{VAS}<5)$, locoregional or systemic infection at the time of inclusion, coagulation disorders.

\subsection{Procedure and Anesthesia}

Procedures were performed during a short hospital stay. CT guidance was used for targeting lesions.

Strict local anesthetic protocol was followed as previsoulsy described [22] and included:

1. Needle pathway local anesthetic injection (a mixture of fast- and slow-acting anesthetic (lidocaine hydrochloride $1 \%(1 / 3)$ and ropivacaine hydrochloride $0.25 \%(2 / 3)$ : from skin entry point to tumor, associated to an intratumoral block with the same mixture. Quantities of injectant depended on both tumor size and patient's tolerance, without exceeding dose limits [10].

2. Inhalation of nitrous oxide throughout the procedure.

3. IV administration of paracetamol ( $1 \mathrm{~g})$ started $5 \mathrm{~min}$ prior to procedure. IV injection of nalbuphin $(20 \mathrm{mg})$ could be added on demand in case of persisting pain.

\subsection{RFA Technique}

Strict aseptic technique was assured during the procedure. From one to two bipolar RF needles (17 G diameter exposed tip, 20-30 mm, Celon Prosurge, Teltow, Germany) were introduced coaxially through a 13 gauge biopsy needle ( $t^{\prime} \mathrm{CD}$ II, Thiebaud, Thonon, France). Technical success was defined as the ability to successfully place the RFA probe in the center of the lesion in case of a unique lesion, and at least $1.5 \mathrm{~cm}$ distance between probes in case of several needles, and to perform RFA (Figures 1 and 2). Duration and power of 
RFA depended on tumor size, manufacturer's recommendation, patient's tolerance and our own experience.

Table 1. Patient and lesion characteristics.

\begin{tabular}{|c|c|c|c|c|c|c|c|}
\hline Sex/Age & Primary & Lesion Level & Size (mm) & Type & $\begin{array}{l}\text { Soft-Tissue } \\
\text { Involvement }\end{array}$ & $\begin{array}{c}\text { Posterior } \\
\text { Wall } \\
\text { Involvement }\end{array}$ & Cementoplasty \\
\hline $1-\mathrm{M} / 46$ & melanoma & body T6 & $16 \times 25 \times 12$ & lytic & no & yes & yes \\
\hline 2-M/54 & lung & body L1 & $29 \times 35 \times 13$ & lytic & no & no & yes \\
\hline 3-M/58 & lung & body L2 & $30 \times 30 \times 26$ & lytic & no & no & yes \\
\hline \multirow[t]{2}{*}{$4-\mathrm{M} / 56$} & lung & body T7 & $15 \times 26 \times 13$ & lytic & no & no & yes \\
\hline & & body T8 & $17 \times 28 \times 12$ & lytic & no & no & yes \\
\hline $5-\mathrm{F} / 75$ & lung & body L1 & $61 \times 58 \times 20$ & lytic & yes & yes & yes \\
\hline $6-\mathrm{F} / 55$ & lung & body L5 & $25 \times 12 \times 33$ & lytic & yes & no & yes \\
\hline 7-M/60 & lung & pedicle L T12 & $54 \times 32 \times 20$ & lytic & yes & no & no \\
\hline 8-M/72 & lung & $\begin{array}{c}\mathrm{R} \text { Transverse } \\
\text { process } \mathrm{T} 5\end{array}$ & $16 \times 19 \times 13$ & lytic & yes & no & no \\
\hline 9-M/59 & lung & body T10 & $32 \times 35 \times 20$ & lytic & yes & no & yes \\
\hline $10-\mathrm{M} / 76$ & prostate & body L3 & $32 \times 27 \times 19$ & osteoblastic & no & yes & yes \\
\hline $11-\mathrm{M} / 56$ & urothelial & body L3 & $13 \times 13 \times 12$ & lytic & yes & no & no \\
\hline $12-\mathrm{M} / 74$ & prostate & body T9 & $16 \times 19 \times 12$ & osteoblastic & no & yes & no \\
\hline $13-\mathrm{M} / 59$ & kidney & body L2 & $14 \times 15 \times 14$ & lytic & yes & no & yes \\
\hline $14-\mathrm{M} / 44$ & $\begin{array}{l}\text { head and } \\
\text { neck }\end{array}$ & body T12 & $15 \times 13 \times 8$ & osteoblastic & no & no & no \\
\hline \multirow[t]{2}{*}{ 15-M/61 } & $\begin{array}{l}\text { hepatocellular } \\
\text { carcinoma }\end{array}$ & pedicle L L5 & $38 \times 47 \times 22$ & lytic & yes & yes & no \\
\hline & & $\begin{array}{l}\text { pedicle L L4 } \\
\text { et L5 }\end{array}$ & $54 \times 30 \times 33$ & lytic & yes & yes & no \\
\hline $16-\mathrm{F} / 57$ & breast & body T12 & $40 \times 57 \times 11$ & mixt & no & no & yes \\
\hline 17-M/75 & pancreas & $\begin{array}{l}\text { R pedicle } \\
\text { C7/T1 }\end{array}$ & $55 \times 44 \times 40$ & lytic & yes & yes & no \\
\hline $18-\mathrm{M} / 63$ & lung & pedicle R L2 & $15 \times 20 \times 16$ & lytic & no & yes & no \\
\hline 19-F/69 & neuroendocrine & sacrum L S1 & $28 \times 31 \times 20$ & lytic & no & no & no \\
\hline 20-M/61 & pancreas & body L2 & $45 \times 40 \times 22$ & lytic & no & no & yes \\
\hline $21-F / 35$ & breast & body L3 & $25 \times 29 \times 21$ & lytic & no & no & yes \\
\hline \multirow[t]{2}{*}{$22-F / 46$} & colorectal & body L4 & $22 \times 38 \times 24$ & lytic & yes & no & yes \\
\hline & & SI right & $19 \times 30 \times 18$ & lytic & no & no & yes \\
\hline $23-\mathrm{M} / 76$ & colorectal & body L1 & $21 \times 18 \times 13$ & lytic & no & no & yes \\
\hline $24-\mathrm{M} / 63$ & colorectal & $\begin{array}{l}\text { L Transverse } \\
\text { process T6 }\end{array}$ & $10 \times 10 \times 10$ & lytic & yes & no & no \\
\hline \multirow[t]{2}{*}{$25-F / 66$} & colorectal & sacrococcygeal & $56 \times 55 \times 71$ & lytic & yes & yes & no \\
\hline & colorectal & sacrococcygeal & $50 \times 56 \times 45$ & lytic & yes & yes & no \\
\hline
\end{tabular}



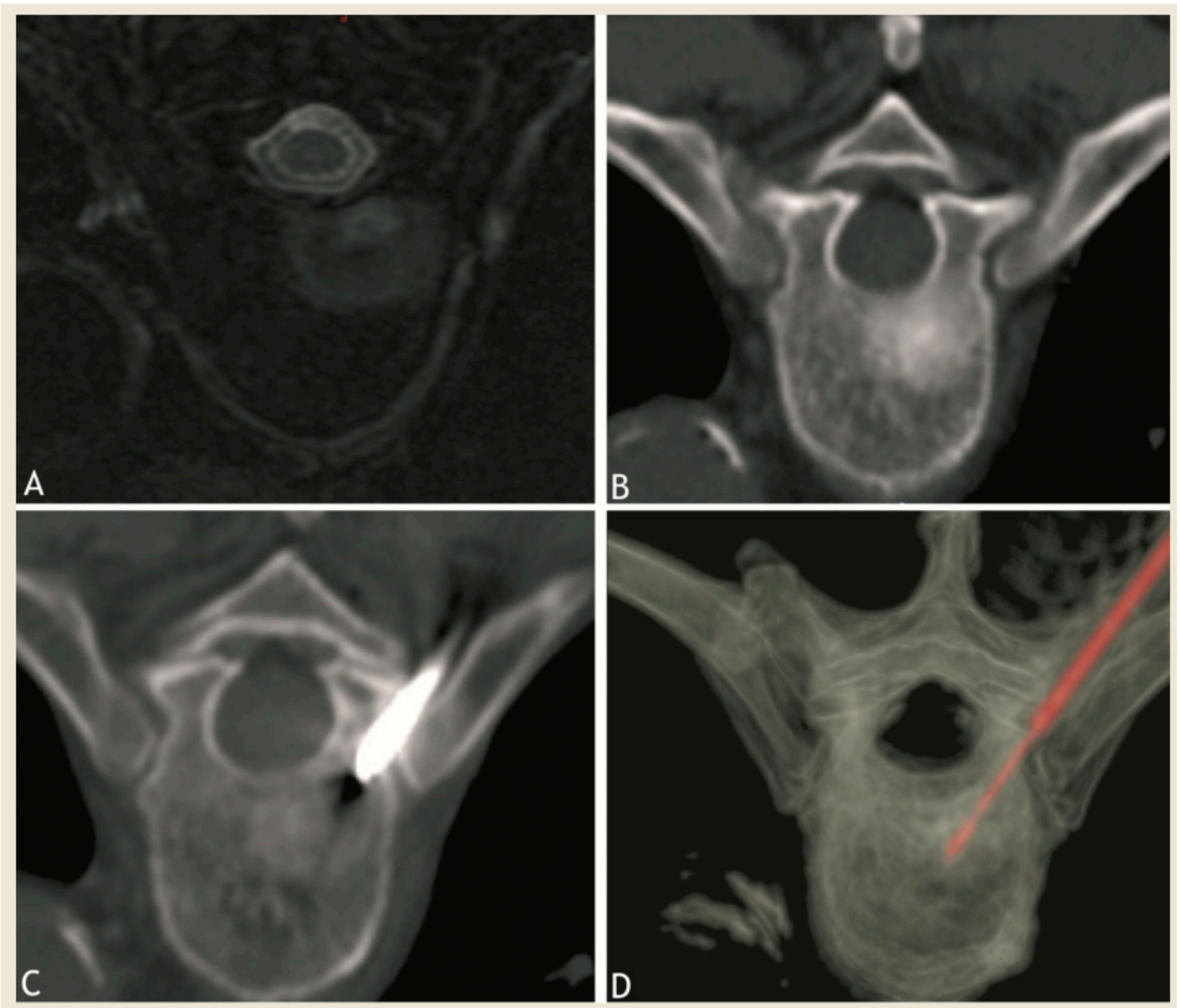

Figure 1. Axial MRI after gadolinium injection (A) and CT (B) showing a sclerotic-enhancing lesion of the vertebral body of fifth thoracic vertebra. (C,D): CT images showing the radiofrequency probe at target site in the lesion during thermoablation session.

Multiple RFA cycles and/or multiple needle approaches were performed for large lesions $(>4 \mathrm{~cm}$ ) (see Table 1). In case of adjunct cementoplasty, cement injection was performed through the same needle after RFA probe retrieval, and an average of $4 \mathrm{~mL}$ of acrylic cement was injected. In case of proximity to a neural structure, a thermocouple was used to monitor intraprocedural temperature.

\subsection{Pain Assessment}

Visual analogue scale scoring was used to assess procedure effectiveness: before procedure, at day 1, 1st month, 3rd month, 6th month, and 12th month. A 50\% pain decrease at one month on VAS was considered as a positive response. Intraprocedural pain and tolerance to the procedure was measured on a $0-2$ scale: $0=$ no pain, $1=$ tolerable pain, $2=$ intolerable pain.v 

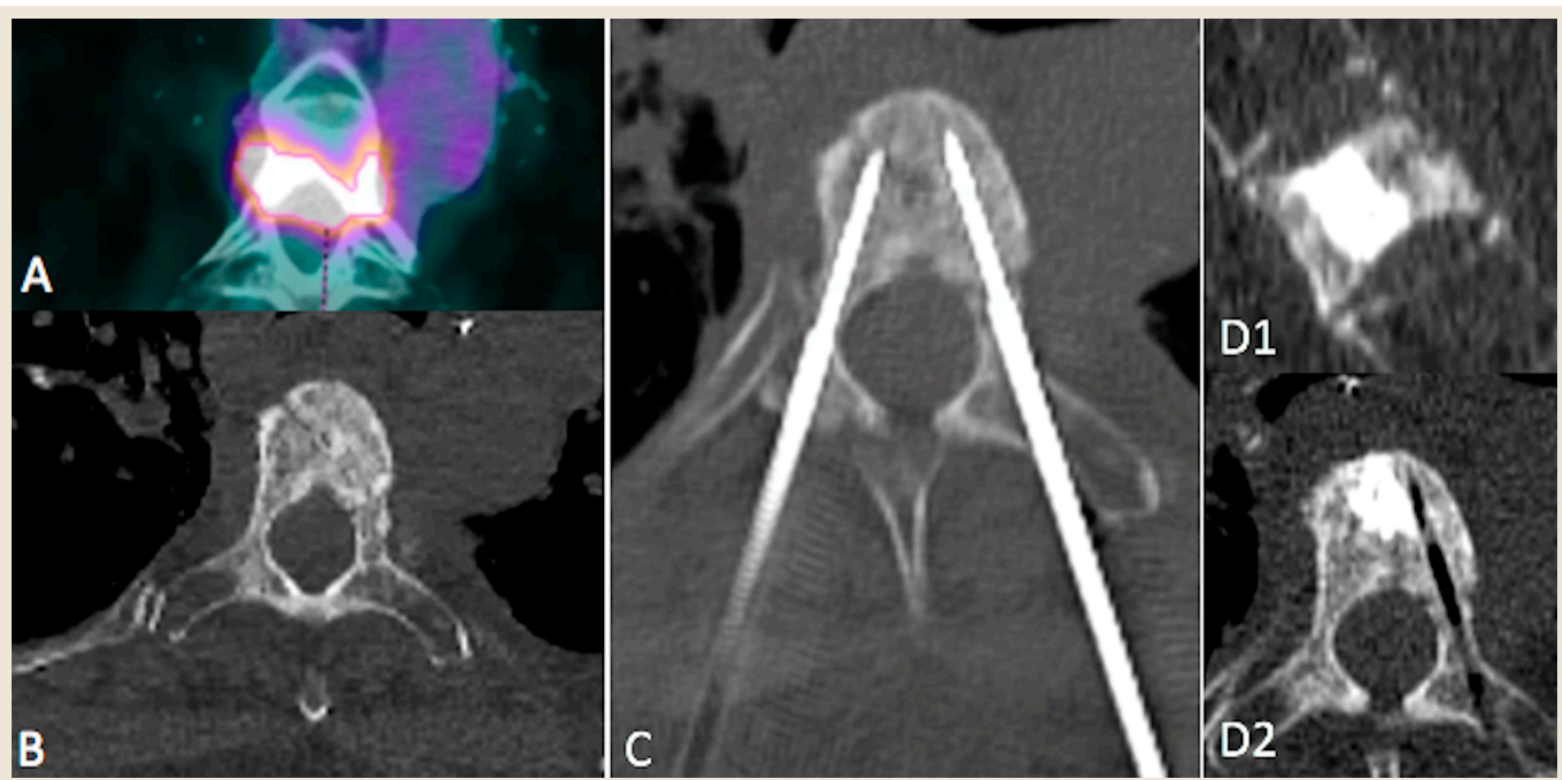

Figure 2. Example of a patient presenting with a unique painful, T4 hypermetabolic colorectal cancer sclerotic metastasis $(\mathbf{A}, \mathbf{B})$ treated with bipedicular bipolar radiofrequency ablation (C) and subsequent vertebroplasty in sagittal (D1) and axial (D2) planes.

\section{Statistical Analysis}

Continuous variables were expressed as mean $+/-\mathrm{SD}$. The Shapiro-Wilk test was used to determine whether variables came from a normally distributed population. A Friedmann's variance analysis and Student's $t$ test on paired samples were performed between the groups. A value of $p<0.05$ was considered significant.

\section{Results}

\subsection{Procedure}

The technical success rate was $100 \%$. The average duration RFA procedure was $23+/-9.9$ min. A thermocouple was used in 17 cases, 12 cases of radicular nerve monitoring, and 5 cases of epidural monitoring. Multiples needles were performed in: seven cases with two needles and two cases with three needles. No clinical complications were noted during or after procedure. Analysis of postprocedural CT did not reveal the immediate procedure related complications.

Vertebroplasty was performed in seven cases of pathological fracture and nine cases of fracture prevention. In these cases of vertebroplasty, 11 of 16 postprocedural CT showed minor cement leakage with no clinical expression (prevertebral, epidural or intradiscal).

Constant oral contact was made with the patient during the whole procedure especially during the ablation phase, and the patient was told to alert, in case of pain radiation in the legs. Moreover, every minute, sensitive and motor testing was performed in order to ensure the lack of neurological damage.

\subsection{Pain}

The per procedure tolerance was rated as follows: 0 for 16 procedures $(55 \%, 16 / 29), 1$ for $12(41 \%, 12 / 29)$ and 2 for 1 procedure $(3 \%, 1 / 29)$.

One patient was lost to follow up at 12 months. Mean VAS before the procedure was $8.4 / 10$. A significant reduction in pain was obtained in $24 / 29(83 \%)$ procedures at 1 month. Details are summarized in Tables 1 and 2 and illustrated in Figure 3. 
Table 2. Detailed VAS follow-up data.

\begin{tabular}{|c|c|c|c|c|c|c|c|}
\hline \multirow[t]{2}{*}{ Patient } & \multicolumn{6}{|c|}{ VAS Scores } & \multirow[t]{2}{*}{ Tolerance } \\
\hline & Before Procedure & $24 \mathrm{~h}$ & 1 Month & 3 Month & 6 Month & 12 Month & \\
\hline 1 & 10 & 5 & 0 & 1 & 2 & _ & 1 \\
\hline 2 & 10 & 1 & 2 & 0 & 0 & - & 0 \\
\hline 3 & 9 & 2 & 1 & 3 & 4 & 0 & 0 \\
\hline \multirow[t]{2}{*}{4} & 9 & 2 & 2 & 0 & 0 & 0 & 1 \\
\hline & 8 & 0 & 0 & 0 & - & - & 1 \\
\hline 5 & 10 & 1 & 0 & 2 & $\overline{1}$ & $\overline{0}$ & 0 \\
\hline 6 & 9 & 4 & 0 & 4 & 5 & lost & 0 \\
\hline 7 & 9 & 7 & 0 & 6 & 3 & 4 & 0 \\
\hline 8 & 10 & 0 & 9 & 7 & _- & _- & 1 \\
\hline 9 & 10 & 7 & 3 & - & - & - & 1 \\
\hline 10 & 9 & 2 & 0 & $\overline{0}$ & $\overline{4}$ & $\overline{4}$ & 1 \\
\hline 11 & 8 & 0 & 0 & 4 & 2 & 3 & 1 \\
\hline 12 & 8 & 0 & 0 & 0 & 0 & 0 & 0 \\
\hline 13 & 9 & 0 & 3 & 0 & 0 & 5 & 0 \\
\hline 14 & 6 & 0 & 0 & 0 & 0 & 0 & 0 \\
\hline \multirow[t]{2}{*}{15} & 8 & 3 & 4 & 4 & 0 & 0 & 1 \\
\hline & 4 & 4 & 4 & - & - & - & 0 \\
\hline 16 & 8 & 0 & 0 & 0 & 2 & _ & 1 \\
\hline 17 & 8 & 8 & 8 & - & _ & - & 2 \\
\hline 18 & 7 & 4 & 3 & - & - & - & 0 \\
\hline 19 & 9 & 2 & 3 & 1 & 0 & 0 & 1 \\
\hline 20 & 6 & 0 & 0 & _ & _ & - & 0 \\
\hline 21 & 9 & 0 & 2 & 4 & 5 & 5 & 0 \\
\hline \multirow[t]{2}{*}{22} & 9 & 1 & 2 & 1 & 3 & 1 & 0 \\
\hline & 9 & 2 & 1 & 2 & 2 & 2 & 1 \\
\hline 23 & 9 & 4 & 0 & 0 & 1 & _ & 1 \\
\hline 24 & 8 & 4 & 3 & 3 & 3 & 3 & 0 \\
\hline \multirow[t]{2}{*}{25} & 9 & 1 & 2 & 0 & 0 & 0 & 0 \\
\hline & 8 & 0 & 0 & 0 & - & - & 0 \\
\hline Mean & 8.4 & 2.2 & 1.8 & 1.8 & 1.9 & 1.8 & \\
\hline Standard Deviation & \pm 1.4 & \pm 2.4 & \pm 2.3 & \pm 2.2 & \pm 1.8 & \pm 2.1 & \\
\hline
\end{tabular}

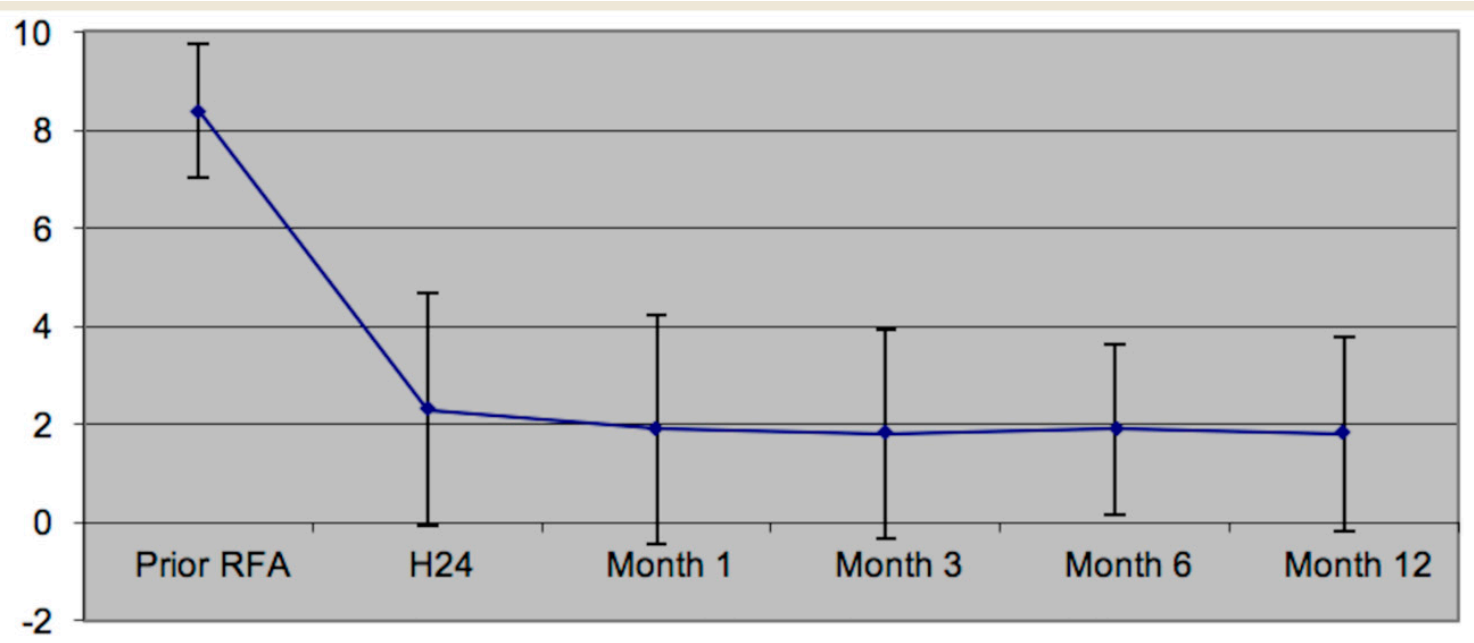

Figure 3. Mean visual analog scale as a function of time.

Therapeutic failures on pain palliation were observed in three procedures with an advanced stage of disease. In each case, lesions were very large with significant prevertebral soft tissue and foraminal invasion. In five other patients, a pain decrease of less than 50\% was noted: at 1 month (one patient), at 3 months (two patients), at 6 months (two patients) 
and at 1 year (two patients). Significant tumor lesion growth or new lesions were observed in these patients.

\section{Discussion}

Many therapeutic options are available for patient suffering from spinal metastasis.. Specific medication may lead to well-known side effects, gastrointestinal (NSAIDs, corticosteroids and opioids), neurological (morphine-impaired consciousness, etc.) or intolerance. Chemotherapy has systemic toxic effects and a delayed action. External beam radiotherapy remains the treatment of choice for the palliative treatment of metastatic bone tumors but is not effective in $20-30 \%$ cases (10 patients in our series). Furthermore, its analgesic effect is delayed 12-20 weeks [8]. Surgery is often not appropriate in late-stage cancer patient as it remains very invasive with a long recovery. Percutaneous RFA treatment offers a useful alternative for patients in palliative care units as pain improvement occurs very rapidly after treatment, as shown by several previous studies which have reported the usefulness, safety and rapid pain release after RFA for spinal lesions $[19,20,23,24]$. The choice of bipolar radiofrequency was made on the well-known advantages of bipolar RFA as opposed to monopolar RF-better control of the ablation zone [25] and no risk of skin burning due to grounding pads not contraindicated in pacemakers wearers $[13,16]$. Moreover, microwave ablation, although it has been reported to be feasible in vertebral lesions [14], presents higher risks of complications [26].

The results of our study are consistent with those of the recent literature [27]. Indeed, $82 \%$ of patients had an analgesic satisfying results at 1 month with significant long term pain palliation. Pain alleviation was obtained immediately after procedure and ensured significant lasting pain relief. Thus, end-of-life quality was improved in these patients suffering from intractable pain. The recovery of walking was possible for all patients (helping prevent decubitus complications, which are not rare). These results were obtained with a minimally invasive procedure under local anesthesia and nitrous oxide ventilation, which was very well tolerated by the patients as $>90 \%$ of the patients graded the procedure as either nonpainful or tolerable. These findings are possible because careful attention was made to follow a well-codified anesthetic/pain management protocol which was strictly applied for each patient. Previous studies on RFA in the bone metastases report either the use of general anesthesia or conscious sedation [18,28]. However, a previous study assessing radiofrequency of extra axial metastasis has shown the feasibility of RF procedure under local anesthesia alone [13]. Local anesthesia has several advantages over general anesthesia: it allows per procedural clinical monitoring which helps to evaluate procedure tolerance and allows detection of possible neurological complications; this advantage is major, as spine thermal ablation may result in neurological impairment [29], and while previous authors have advised the use protective measures with good results [30,31], authors have already reported the use of local anesthesia and clinical intraprocedural assessment with microwave ablations, with excellent results [14].

The anxiolytic effect of visual, auditory and tactile distraction techniques was constantly performed by operators and technicians, as already demonstrated in other surgical fields [32], which is reinforced by the use of nitrous oxide inhalation which presents both an anxiolytic and analgesic effect [33].

Finally, the absence of general anesthesia may broaden indications to patients for which general anesthesia may be contraindicated due to a frail condition. This is probably the most important added value of local anesthesia as it has been shown that palliative radiotherapy should be performed in patients with a short life expectancy [34]. Therefore, and because pain relief is obtained immediately after procedure with RFA (as opposed to several weeks with radiation therapy), RFA under local anesthesia should evidently be considered as the method of choice in patients in the palliative care.

Our study however has several limitations. The results are retrospective based on consultation data. The study relies on a small study sample, with a lack of uniformity 
of the included lesions (size and type). Finally, no data were available on pain therapy modifications after the procedure, which may have introduced an outcome bias.

\section{Conclusions}

Bipolar RFA is a safe and effective treatment of painful refractory vertebral metastases in patients in palliative care. It is well tolerated under local anesthesia with nitrous oxide inhalation. This approach allows for a regular intraprocedural clinical examination and may help avoid possible surrounding neural damage, such as cord injury. Immediate pain relief is observed, improving the patient's quality of live, which is desirable in patients with a limited life expectancy. Such results are a priority in pain palliation patients.

Further studies comparing RF alone versus RF combined with vertebroplasty are needed to establish the benefit of a combining RF and vertebroplasty.

Author Contributions: Conceptualization, B.K., A.K.; methodology, G.A., D.-A.B.; software, G.A.; validation, A.K., B.K.; formal analysis, D.-A.B., G.A.; data curation, G.H.; writing-original draft preparation, G.A., D.-A.B.; writing-review and editing, G.A., A.K. and B.K.; supervision, B.K., F.H.C. All authors have read and agreed to the published version of the manuscript.

Funding: This research received no external funding.

Institutional Review Board Statement: IRB approval was obtained.

Informed Consent Statement: Informed consent was obtained from all subjects involved in the study.

Data Availability Statement: All the data are available from the corresponding author upon reasonable request.

Conflicts of Interest: The authors declare no conflict of interest.

\section{References}

1. Sciubba, D.M.; Petteys, R.J.; Dekutoski, M.B.; Fisher, C.G.; Fehlings, M.G.; Ondra, S.L.; Rhines, L.D.; Gokaslan, Z.L. Diagnosis and management of metastatic spine disease. A review. J. Neurosurg. Spine 2010, 13, 94-108. [CrossRef]

2. Coleman, R.E. Skeletal complications of malignancy. Cancer 1997, 80, 1588-1594. [CrossRef]

3. Coleman, R.E. Metastatic bone disease: Clinical features, pathophysiology and treatment strategies. Cancer Treat. Rev. 2001, 27, 165-176. [CrossRef]

4. Coleman, R.E. Clinical features of metastatic bone disease and risk of skeletal morbidity. Clin. Cancer Res. 2006, 12, 6243s-6249s. [CrossRef]

5. Bach, F.; Larsen, B.H.; Rohde, K.; Borgesen, S.E.; Gjerris, F.; Boge-Rasmussen, T.; Agerlin, N.; Rasmusson, B.; Stjernholm, P.; Sorensen, P.S. Metastatic spinal cord compression. Occurrence, symptoms, clinical presentations and prognosis in 398 patients with spinal cord compression. Acta Neurochir. 1990, 107, 37-43. [CrossRef]

6. Helweg-Larsen, S.; Sorensen, P.S. Symptoms and signs in metastatic spinal cord compression: A study of progression from first symptom until diagnosis in 153 patients. Eur. J. Cancer 1994, 30, 396-398. [CrossRef]

7. Spiegel, D.; Sands, S.; Koopman, C. Pain and depression in patients with cancer. Cancer 1994, 74, 2570-2578. [CrossRef]

8. Agarawal, J.P.; Swangsilpa, T.; van der Linden, Y.; Rades, D.; Jeremic, B.; Hoskin, P.J. The role of external beam radiotherapy in the management of bone metastases. Clin. Oncol. 2006, 18, 747-760. [CrossRef] [PubMed]

9. Lutz, S.; Berk, L.; Chang, E.; Chow, E.; Hahn, C.; Hoskin, P.; Howell, D.; Konski, A.; Kachnic, L.; Lo, S.; et al. Palliative radiotherapy for bone metastases: An ASTRO evidence-based guideline. Int. J. Radiat. Oncol. Biol. Phys. 2011, 79, 965-976. [CrossRef]

10. Poulsen, H.S.; Nielsen, O.S.; Klee, M.; Rorth, M. Palliative irradiation of bone metastases. Cancer Treat. Rev. 1989, 16, 41-48. [CrossRef]

11. Anselmetti, G.C.; Manca, A.; Ortega, C.; Grignani, G.; Debernardi, F.; Regge, D. Treatment of extraspinal painful bone metastases with percutaneous cementoplasty: A prospective study of 50 patients. Cardiovasc. Interv. Radiol. 2008, 31, 1165-1173. [CrossRef]

12. Saliou, G.; Kocheida, E.M.; Lehmann, P.; Depriester, C.; Paradot, G.; Le Gars, D.; Balut, A.; Deramond, H. Percutaneous vertebroplasty for pain management in malignant fractures of the spine with epidural involvement. Radiology 2010, 254, 882-890. [CrossRef]

13. Alemann, G.; Kastler, A.; Barbe, D.A.; Aubry, S.; Kastler, B. Treatment of painful extraspinal bone metastases with percutaneous bipolar radiofrequency under local anesthesia: Feasibility and efficacy in twenty-eight cases. J. Palliat. Med. 2014, 17, 947-952. [CrossRef] [PubMed]

14. Kastler, A.; Alnassan, H.; Aubry, S.; Kastler, B. Microwave thermal ablation of spinal metastatic bone tumors. J. Vasc. Interv. Radiol. 2014, 25, 1470-1475. [CrossRef] [PubMed] 
15. Kastler, A.; Alnassan, H.; Pereira, P.L.; Alemann, G.; Barbe, D.A.; Aubry, S.; Tiberghien, F.; Kastler, B. Analgesic effects of microwave ablation of bone and soft tissue tumors under local anesthesia. Pain Med. 2013, 14, 1873-1881. [CrossRef] [PubMed]

16. Hoffmann, R.T.; Jakobs, T.F.; Trumm, C.; Weber, C.; Helmberger, T.K.; Reiser, M.F. Radiofrequency ablation in combination with osteoplasty in the treatment of painful metastatic bone disease. J. Vasc. Interv. Radiol. 2008, 19, 419-425. [CrossRef]

17. Callstrom, M.R.; Atwell, T.D.; Charboneau, J.W.; Farrell, M.A.; Goetz, M.P.; Rubin, J.; Sloan, J.A.; Novotny, P.J.; Welch, T.J.; Maus, T.P.; et al. Painful metastases involving bone: Percutaneous image-guided cryoablation-prospective trial interim analysis. Radiology 2006, 241, 572-580. [CrossRef] [PubMed]

18. Clarencon, F.; Jean, B.; Pham, H.P.; Cormier, E.; Bensimon, G.; Rose, M.; Maksud, P.; Chiras, J. Value of percutaneous radiofrequency ablation with or without percutaneous vertebroplasty for pain relief and functional recovery in painful bone metastases. Skelet. Radiol. 2011, 42, 25-36. [CrossRef]

19. Munk, P.L.; Rashid, F.; Heran, M.K.; Papirny, M.; Liu, D.M.; Malfair, D.; Badii, M.; Clarkson, P.W. Combined cementoplasty and radiofrequency ablation in the treatment of painful neoplastic lesions of bone. J. Vasc. Interv. Radiol. 2009, 20, 903-911. [CrossRef]

20. Toyota, N.; Naito, A.; Kakizawa, H.; Hieda, M.; Hirai, N.; Tachikake, T.; Kimura, T.; Fukuda, H.; Ito, K. Radiofrequency ablation therapy combined with cementoplasty for painful bone metastases: Initial experience. Cardiovasc. Interv. Radiol. 2005, 28, 578-583. [CrossRef]

21. Kostuik, J.P. Differential diagnosis and surgical treatment of metastatic spine tumors. In The Adult Spine; Raven Press: New York, NY, USA, 1991; pp. 861-888.

22. Kastler, B. Interventional Radiology in Pain Treatment; Springer: Berlin, Germany, 2007.

23. Thacker, P.G.; Callstrom, M.R.; Curry, T.B.; Mandrekar, J.N.; Atwell, T.D.; Goetz, M.P.; Rubin, J. Palliation of painful metastatic disease involving bone with imaging-guided treatment: Comparison of patients' immediate response to radiofrequency ablation and cryoablation. Am. J. Roentgenol. 2011, 197, 510-515. [CrossRef]

24. Kojima, H.; Tanigawa, N.; Kariya, S.; Komemushi, A.; Shomura, Y.; Sawada, S. Clinical assessment of percutaneous radiofrequency ablation for painful metastatic bone tumors. Cardiovasc. Interv. Radiol. 2006, 29, 1022-1026. [CrossRef] [PubMed]

25. Nakada, S.Y.; Jerde, T.J.; Warner, T.F.; Wright, A.S.; Haemmerich, D.; Mahvi, D.M.; Lee, F.T., Jr. Bipolar radiofrequency ablation of the kidney: Comparison with monopolar radiofrequency ablation. J. Endourol. 2003, 17, 927-933. [CrossRef] [PubMed]

26. Cazzato, R.L.; de Rubeis, G.; de Marini, P.; Dalili, D.; Koch, G.; Auloge, P.; Garnon, J.; Gangi, A. Percutaneous microwave ablation of bone tumors: A systematic review. Eur. Radiol. 2021, 31, 3530-3541. [CrossRef] [PubMed]

27. Angileri, S.A.; Granata, G.; Savoldi, A.P.; Roda, G.M.; Di Meglio, L.; Grillo, P.; Tortora, S.; Arrichiello, A.; Papa, M.; Liguori, A.; et al. Cooled radiofrequency ablation technology for painful bone tumors. Acta Biomed. 2020, 91, e2020007. [CrossRef] [PubMed]

28. Levy, J.; Hopkins, T.; Morris, J.; Tran, N.D.; David, E.; Massari, F.; Farid, H.; Vogel, A.; O'Connell, W.G.; Sunenshine, P.; et al. Radiofrequency Ablation for the Palliative Treatment of Bone Metastases: Outcomes from the Multicenter OsteoCool Tumor Ablation Post-Market Study (OPuS One Study) in 100 Patients. J. Vasc. Interv. Radiol. 2020, 31, 1745-1752. [CrossRef] [PubMed]

29. Tomasian, A.; Gangi, A.; Wallace, A.N.; Jennings, J.W. Percutaneous Thermal Ablation of Spinal Metastases: Recent Advances and Review. Am. J. Roentgenol. 2018, 210, 142-152. [CrossRef]

30. Tsoumakidou, G.; Garnon, J.; Ramamurthy, N.; Buy, X.; Gangi, A. Interest of electrostimulation of peripheral motor nerves during percutaneous thermal ablation. Cardiovasc. Interv. Radiol. 2013, 36, 1624-1628. [CrossRef]

31. Buy, X.; Tok, C.H.; Szwarc, D.; Bierry, G.; Gangi, A. Thermal protection during percutaneous thermal ablation procedures: Interest of carbon dioxide dissection and temperature monitoring. Cardiovasc. Interv. Radiol. 2009, 32, 529-534. [CrossRef]

32. Ing, E.B.; Philteos, J.; Sholohov, G.; Kim, D.T.; Nijhawan, N.; Mark, P.W.; Gilbert, J. Local anesthesia and anxiolytic techniques for oculoplastic surgery. Clin. Ophthalmol. 2019, 13, 153-160. [CrossRef]

33. Li, L.; Pan, Q.; Xu, L.; Lin, R.; Dai, J.; Chen, X.; Jiang, M.; Chen, Z. Comparison of analgesic and anxiolytic effects of nitrous oxide in burn wound treatment: A single-blind prospective randomized controlled trial. Medicine 2019, 98, e18188. [CrossRef] [PubMed]

34. Dennis, K.; Wong, K.; Zhang, L.; Culleton, S.; Nguyen, J.; Holden, L.; Jon, F.; Tsao, M.; Danjoux, C.; Barnes, E.; et al. Palliative radiotherapy for bone metastases in the last 3 months of life: Worthwhile or futile? Clin. Oncol. 2011, 23, 709-715. [CrossRef] [PubMed] 